\title{
Spatial Analysis of Jabal Bekhier Elevation by Using GIS and Remote Sensing
}

\author{
Sabah Hussein Ali Waleed Younis Al-Ubide \\ Remote Sensing Center \\ University of Mosul
}

Received
$17 / 02 / 2010$

\author{
Accepted \\ 27 / 06 / 2010
}

\begin{abstract}
الخلاصة
تعد عملية التعرف ع لى تضاريس سطح الأرض ذو أهمية كبيرة لعلوم الأرض المختلفة،

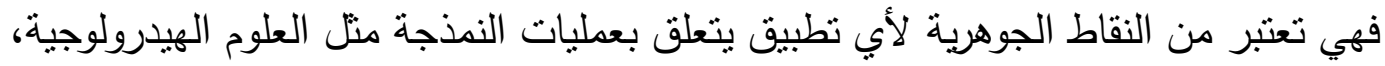
المناخ، الجيومورفولوجي وعلم البيئة. (برنامج)

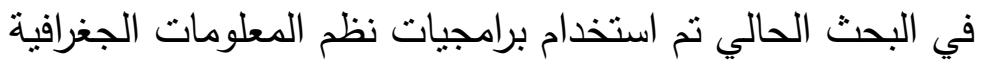

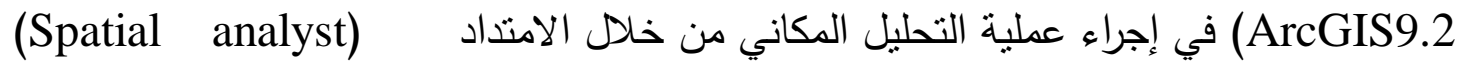

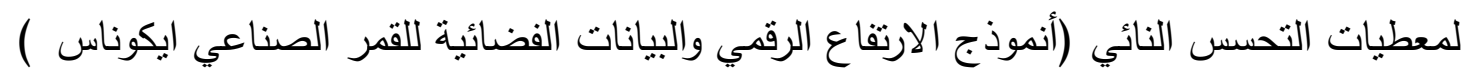

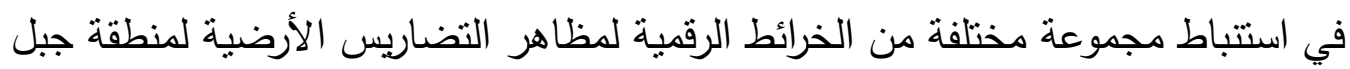

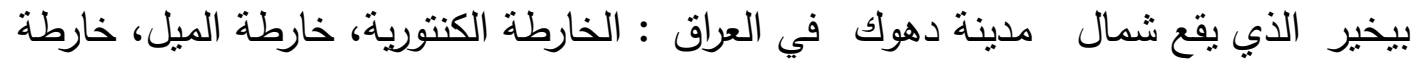

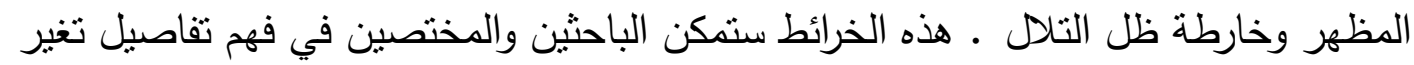

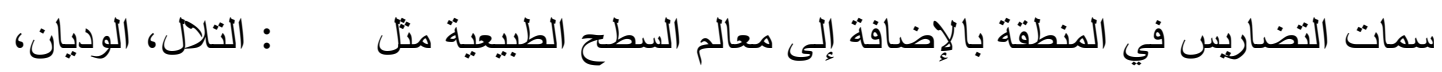

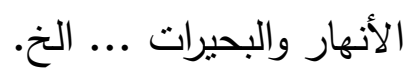

تم تصنيف معالم سطح الأرض الرئيسية في المنطقة الى سبعة وحدات جيومورفولوجية

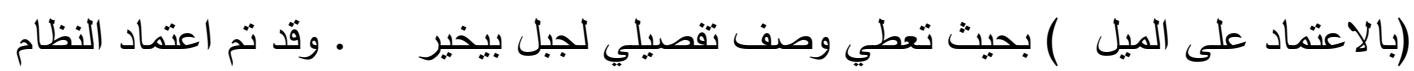

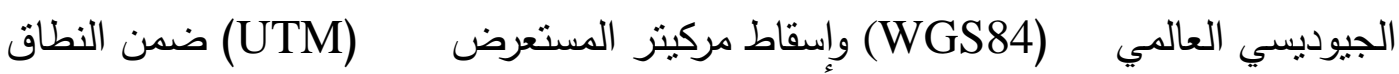
(Zone=38)
\end{abstract}

\begin{abstract}
The knowledge of the surface topography is of major importance to the earth sciences. It is essential in any discipline concerned with process modeling like hydrology, climatology, geomorphology and ecology.

The present study utilized Environmental Systems Research Institute's (ESRI), ArcGIS 9.2 (with the spatial analyst extension) software, remote sensing data (DEM and IKONOS satellite image) of the
\end{abstract}


study area (Jabal Bekhier lies in the north margin of Dohuk Province in the north of Iraq) to extract a different maps of exact geographical locations, like; Contour map, Slop map, Aspect map and Hillshade map.

By using these maps, the land surface of the study area could be realized on a detailed understanding of its terrain variation characteristics also to the natural surface features that including hills, valleys, rivers, lakes ...etc. The landscape features of the study area are classified into seven geomophological units (terrain slop) which are give a detail description of the Jabal Bekhier. All the output maps were defined according to WGS84_UTM_Zone 38N system.

Keyword: Spatial analysis, Bekhier Mount., Slop, Terrain, Aspect, GIS

\section{Introduction:}

Topography is a detailed study or description of a particular place or region. By describing the elevation of each point and its neighborhood, topography is a graphic representation of landscapes natural surface features including hills, valleys, rivers, lakes and such, as principle manmade features. Today, the remote sensing techniques of radar interferometry with Synthetic Aperture Radar systems (SAR) and laser interferometry (LIDAR) are currently the most advanced technology and the most effective way to derivate the terrain elevation and acquire topographic information [1]. DEM is one of the remote sensing data that constructed by using (SAR) interferometry. Therefore, the integration between GIS and remote sensing are become a useful tools in capturing, accumulating, modeling, analyzing and presenting spatial and descriptive data directly or indirectly from satellite image and from available maps. Digital Elevation Models (DEM) is one of the remote sensing data required in many applications as input for GIS to create a different types of thematic maps for landuse and cover, in addition to other terrain information [2]. Applied the spatial analysis for extracting an information about the topographic terrain variation of a certain study area offers the advantage of having information content of spatially distributed data to be analyze [3].

This paper describes our workflow for producing a relational data maps for the adopted study area by the integration process between remote sensing and ArcGIS/Spatial analyst extension. The analytical process was performed on DEM file of the study area to produce digital image maps describe the terrain surfaces, slope, aspect, hill shade of the whole area. The coordinate system of the output maps are defined according to the Universal Transverse Mercator (UTM) coordinate system with specification of north hemisphere at the zone (38) and the World Geodetic System 84 (WGS84) reference ellipsoid, i.e., WGS84_UTM_Zone 38N.

\section{Study area}

The study area is located North of Iraq, to include the Jabal Bekhier to the north west of Dohuk city as shown in figure (1), and approximately between latitudes of (36.875 - 37.0625 degree) and 
longitudes of (42.625-43.187 degree). It covers an area of about (1311) sq.km, and lied to the south western part of folded zone of Iraq. The area is characterized by the present of Assymmetrical Anticline so -called Jabal Bekhier, and extends to a distance of $80 \mathrm{~km}$ from north-west to the south-east direction, which separates two syclines; Sindy Plain in the northeastern and Selivany Plain in the southwestern, the amount of the dip of the southern limb (40-50) degrees while the dip of the northern east limb (20-25) degrees [4]. The form and shape of terrain of the study area can be controlled by the nature and hardnes of the rocks, due to the differential weathering processes, in addition to the effects of the tectonic history of the region, the higher areas of the mountain consisting of prominent rock units which resistance to the weathering processes such that Bekhme, and Pila Spi formations, while the valleys and extending parts of the plains within the rocks of Shiranish, Kolosh, Gercus, Injana, and Fat'ha formations, at which characterized by low resistance to the differential weathering.

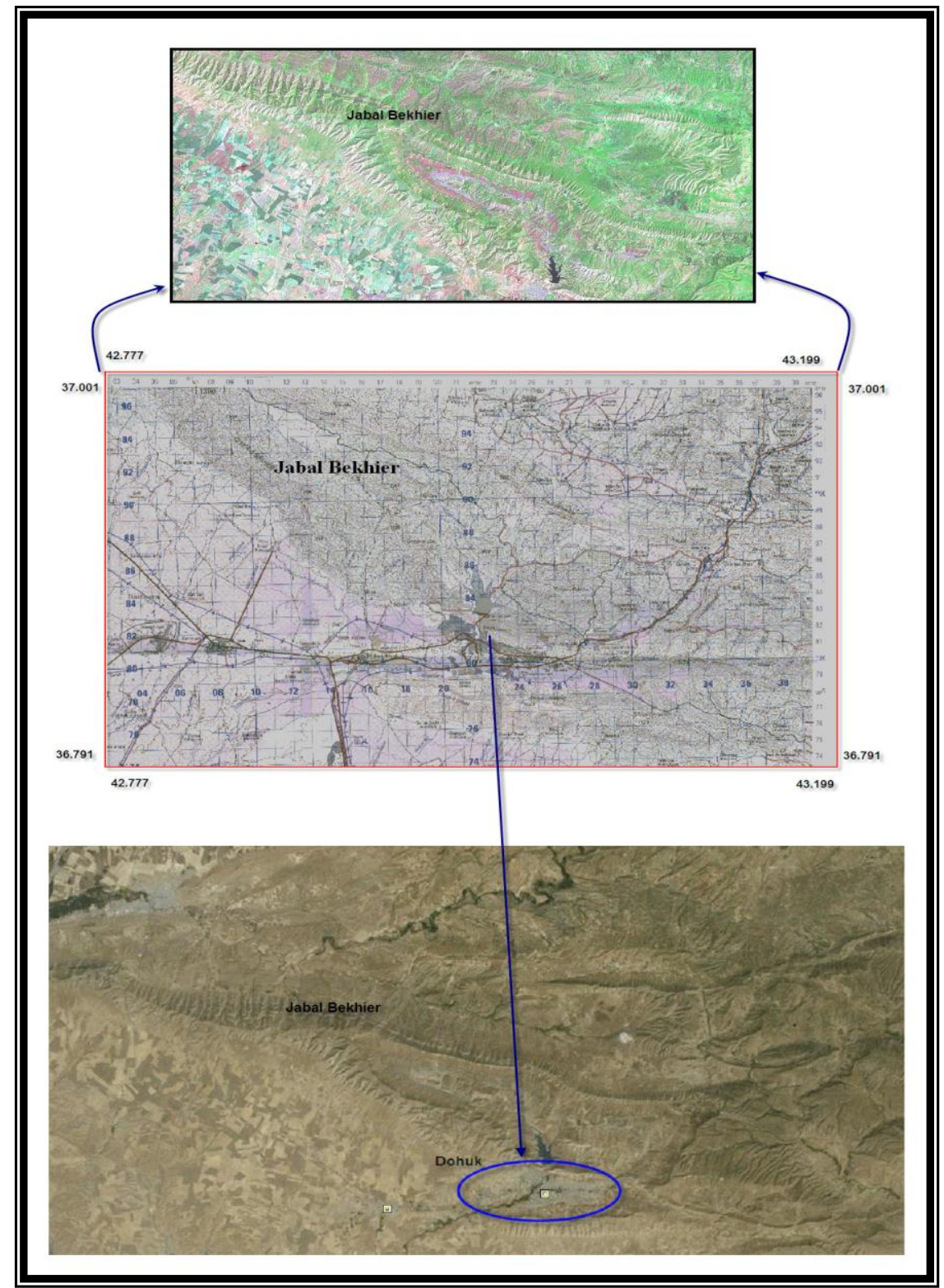

Figure(1): located of the study area 


\section{STRM - DEM}

Digital Elevation Models (DEM) is a computerized representation of the earth's relief. Different formats exists, among the most usual are triangulated irregular networks (TIN), regular grids, contour lines and scattered data points [2]. A DEM is usually described either by a wire frame model or an image matrix in which the value of each pixel is associated with a specific topographic height. A standardized DEM of the most of the earth's surface was produced for the first time by the Shuttle Radar Topographic Mission (SRTM) between 60o N and 56o S Latitudes measured in February 2000, and with spatial resolutions of 30 and 90 meters [1]. WGS84 is used as horizontal and vertical datum; this means that ellipsoidal heights are provided. The DEM is constructed using synthetic aperture radar (SAR) interferometry, meaning that two radar images have been taken from slightly different positions and the surface height is determined using phase differences between images [5], it was measured by using two frequencies (C- and X-bands). However, SRTM's DEM are designed to facilitate research of global processes at regional and local scales, and thus to facilitate the development of higher quality process research. The (DEM) is the most fundamental data type necessary for terrain visualization.

\section{Materials and Methods}

GIS data: There are numerous definitions of GIS, none of which actually describe or explain it sufficiently, but better definition is an information system designed to acquire, store, process and display data referenced by spatial or geographical coordinates. The major advantage of a GIS is that it allows us to identify the spatial relationships between map features as done by this study. A GIS links spatial features with attributes about a particular location on a map. In the present study, the data sources for GIS: Satellite images and DEM.

DEM: Geo-referenced SRTM-DEM in the WGS84_UTM_38N coordinate system was used in this study. The spatial resolution of this DEM is $90 \mathrm{~m}$, it's capture in year 2000 .

Satellite Images: Geo-referenced landsat ETM+ Mosaic (band 1, 2, 7) in WGS84 UTM 38N coordinate system, the spatial resolution is $15 \mathrm{~m}$, it's capture in year 2001.

\section{Software:}

ArcGIS Desktop (version 9.2) - Spatial Analyst extension: Generally, ArcGIS Desktop is the most important program for the GIS application exactly nowadays. The ArcGIS supports the virtual reality program; additionally with ArcScene and ArcGlobe we can consider it a type of 
virtual reality software [6]. The ArcGIS is designed to support a range of different kinds of analysis of geographic information: techniques to examine and explore data from a geographic perspective, to develop and test models, and to present data in ways that lead to greater insight and understanding.

ArcGIS Spatial Analyst, is an optional extension to ArcGIS Desktop provides powerful tools for comprehensive, raster-based spatial analysis [7]. With ArcGIS Spatial Analyst, users can employ a wide range of data formats to combine datasets, interpret new data, and perform complex raster operations such as terrain analysis, surface modeling, surface interpolation, hydrologic analysis, statistical analysis, and much more.

Global Mapper (version 10.0): Global Mapper (GM) provides an ideal view of DEM files which is very useful in the GIS application [8]. GM used in this study as a tool to support the three dimensional display of the DEM data and to export the XYZ file of the study area..

Surfer8: Surfer8 is a contouring and 3D surface mapping software. It easily and accurately transforms XYZ data to create contour maps, 3D surface maps, 3D wireframe maps, shaded relief maps, rainbow color "image" maps, post maps, classed post maps, vector maps, and base maps [9].

\section{Build an elevation raster grid for the study area:}

The elevation information is represented in computers as elevation data in a digital format. Many interpretation of the surface spatial analysis related to the terrain elevation features are performed by employed remote sensing techniques and GIS Package software, where traditional methods do not fulfill the demands for accurate analysis and interpretation.

Surface spatial analysis study was performed on the DEM of the study area with ArcGIS Spatial analyst to derive useful Geospatial information from the study area elevation surfaces such as Slope, Aspect Hillshade and Viewshed maps. These topographic surface maps give the ability to relate the data to real-word elevations and analyze how these varied surfaces might affect the data in question. At the first, the DEM of the study area was prepared from the UTM georeferenced DEM of the Iraq topographically coverage data set by using Global Mapper 10.0 as shown in figure (2). Figure (3) shows the georeferenced output DEM of study area with elevation scale. 
Spatial Analysis of Jabal Bekhier Elevation by Using GIS and Remote Sensing.

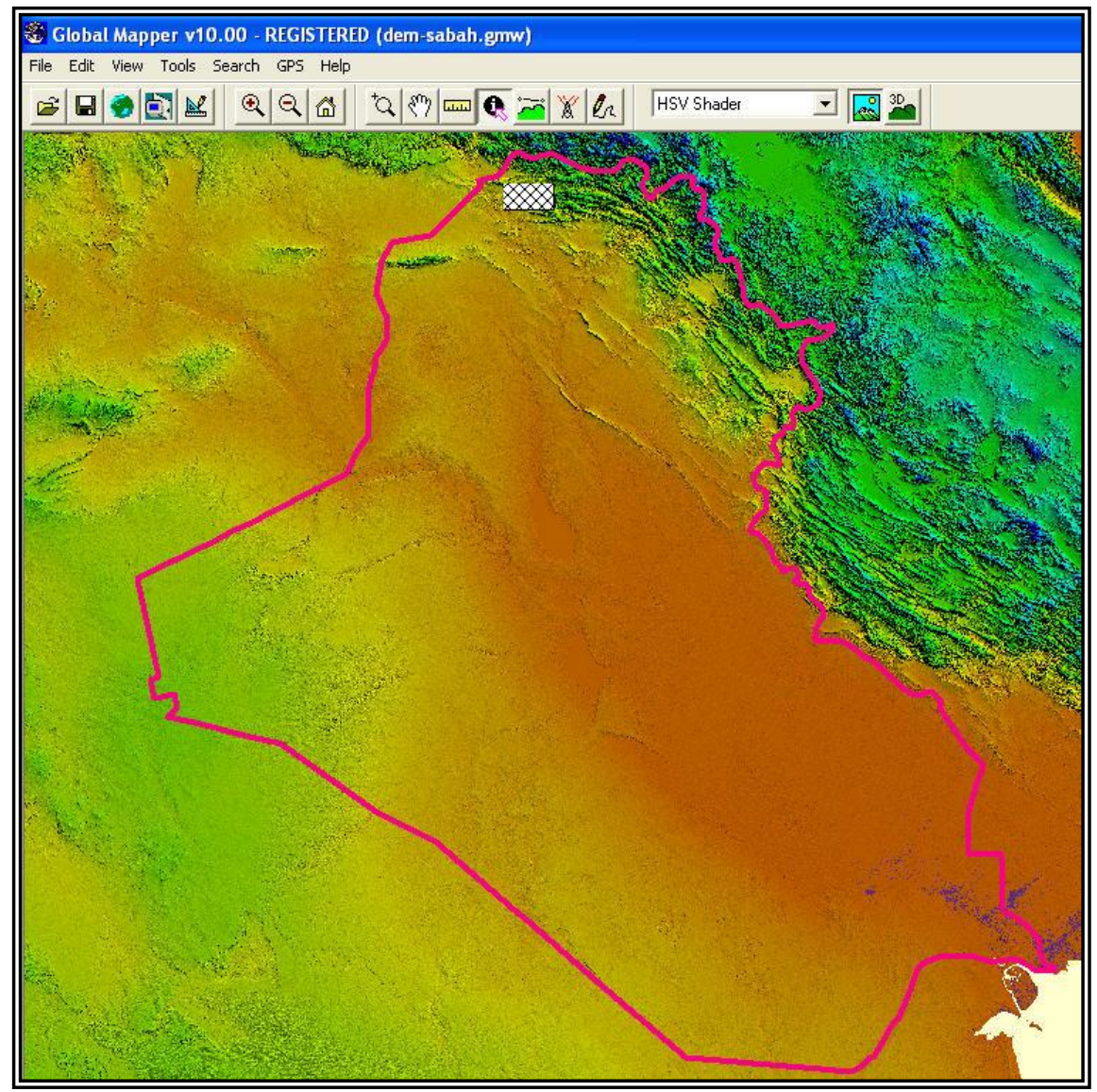

Figure (2): The DEM coverage of the Iraq country

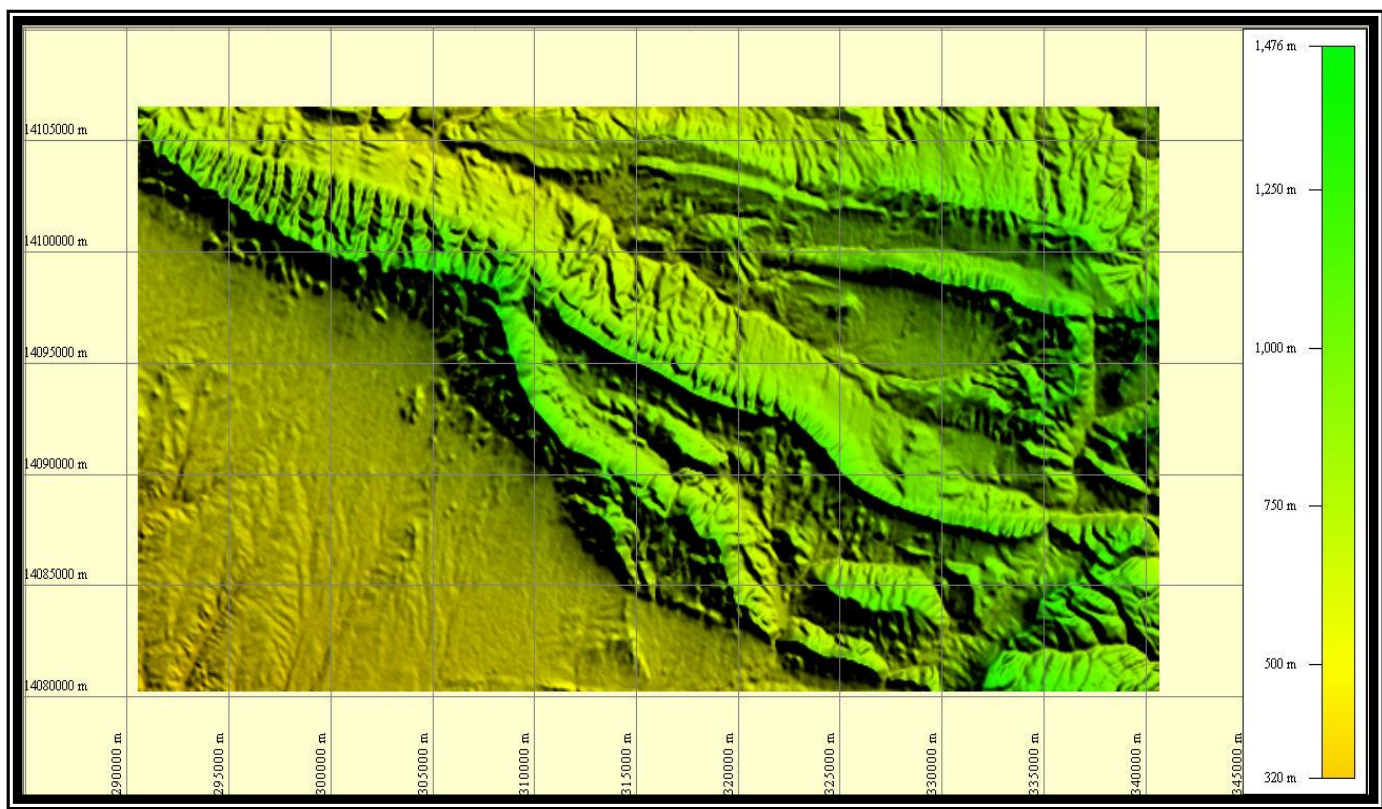

Figure (3): The DEM coverage of the study area 
By using Surfer8.2, the grid of the xyz data format of the DEM was extracted and plotted as a 3D surface to demonstrate the detailed topographic variation of the study area with respect to the coordinate system as shown in figure (4). Table (1) list the statistical data of the grid file extracted from the DEM of the study area.

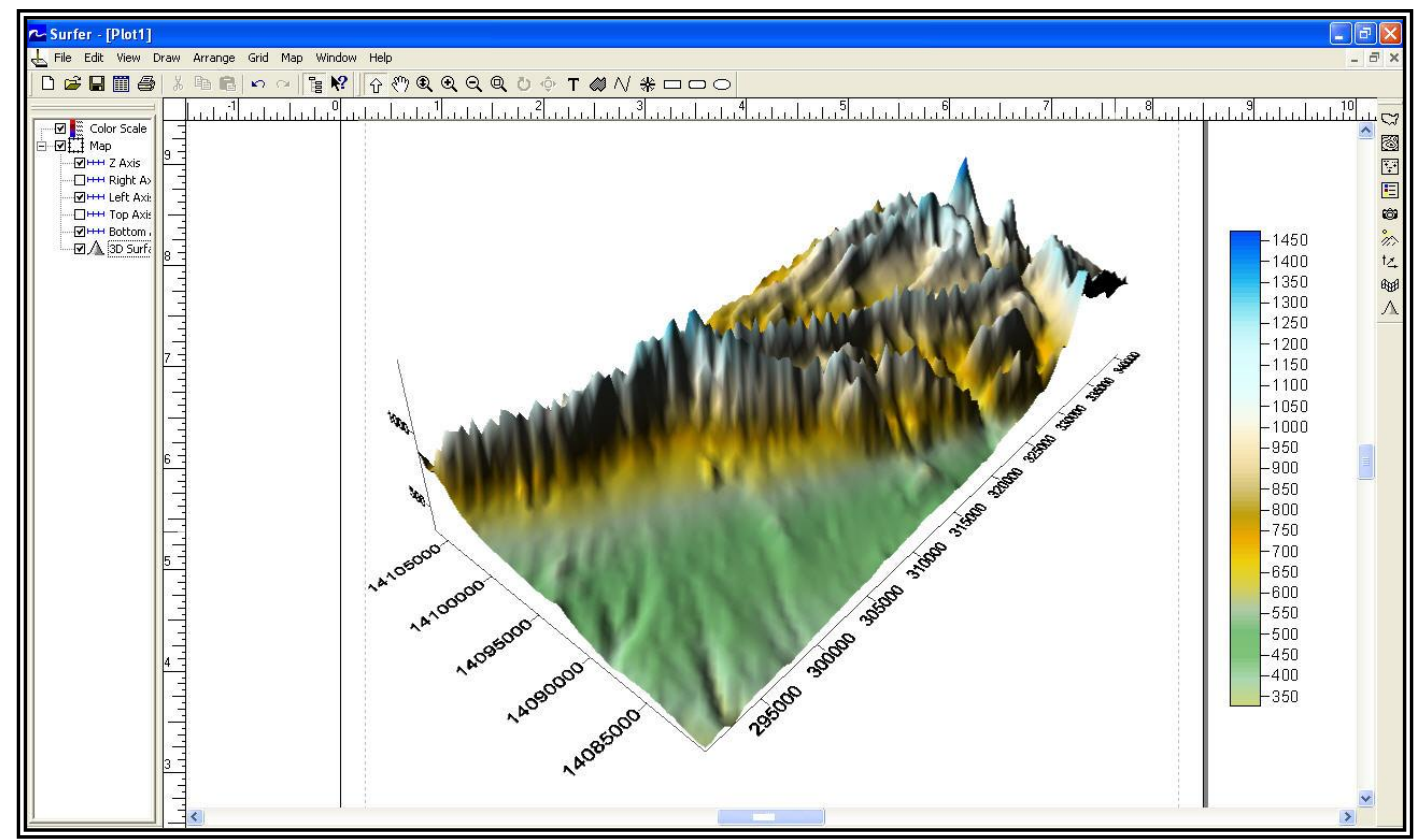

Figure (4): the plotted 3D surface of the study area

Table (1): The statistical data parameters of the extracted grid file of the study area

\begin{tabular}{|llll|}
\hline parameters & $X$ & $Y$ & $Z$ \\
\hline Minimum: & 290593.23 & 4080250.45 & 320.4 \\
25\%-tile: & 303055.91 & 4086823.233 & 575.1 \\
Median: & 315603.95 & 4093396.016 & 780.8 \\
$75 \%$-tile: & 328151.99 & 4099968.799 & 929.5 \\
Maximum: & 340614.67 & 4106456.221 & 1476.9 \\
& & & \\
Midrange: & 315603.95 & 4093353.3355 & 898.65 \\
Range: & 50021.44 & 26205.771 & 1156.5 \\
Interquartile Range: & 25096.08 & 13145.566 & 354.4 \\
Median Abs. Deviation: & 12548.04 & 6572.7830000003 & 174.3 \\
& & & \\
Mean: & 315603.94994037 & 4093353.3358631 & 768.21941304011 \\
Trim Mean (10\%): & 315603.94993754 & 4093353.3358633 & 764.69436939982 \\
Standard Deviation: & 14464.566289669 & 7589.5560661365 & 217.64738059949 \\
Variance: & 209223677.94824 & 57601361.281029 & 47370.382281821 \\
Coef. of Variation: & & & \\
Coef. of Skewness: & & & 0.28331408567012 \\
\hline
\end{tabular}


To build the elevation surface maps, the DEM format must be converted to elevation raster format with cell size $(90 \mathrm{~m})$ and grey scale eight byte (raster DEM) through the ArcToolbox windows in ArcGIS9.2 Desktop as shown in figure (5). The elevation Raster format is a raster stores attributes such as elevation as a grid, it is used to derive surfaces representing landscape surfaces such as slop, Hillshade, aspect ..etc. [10].

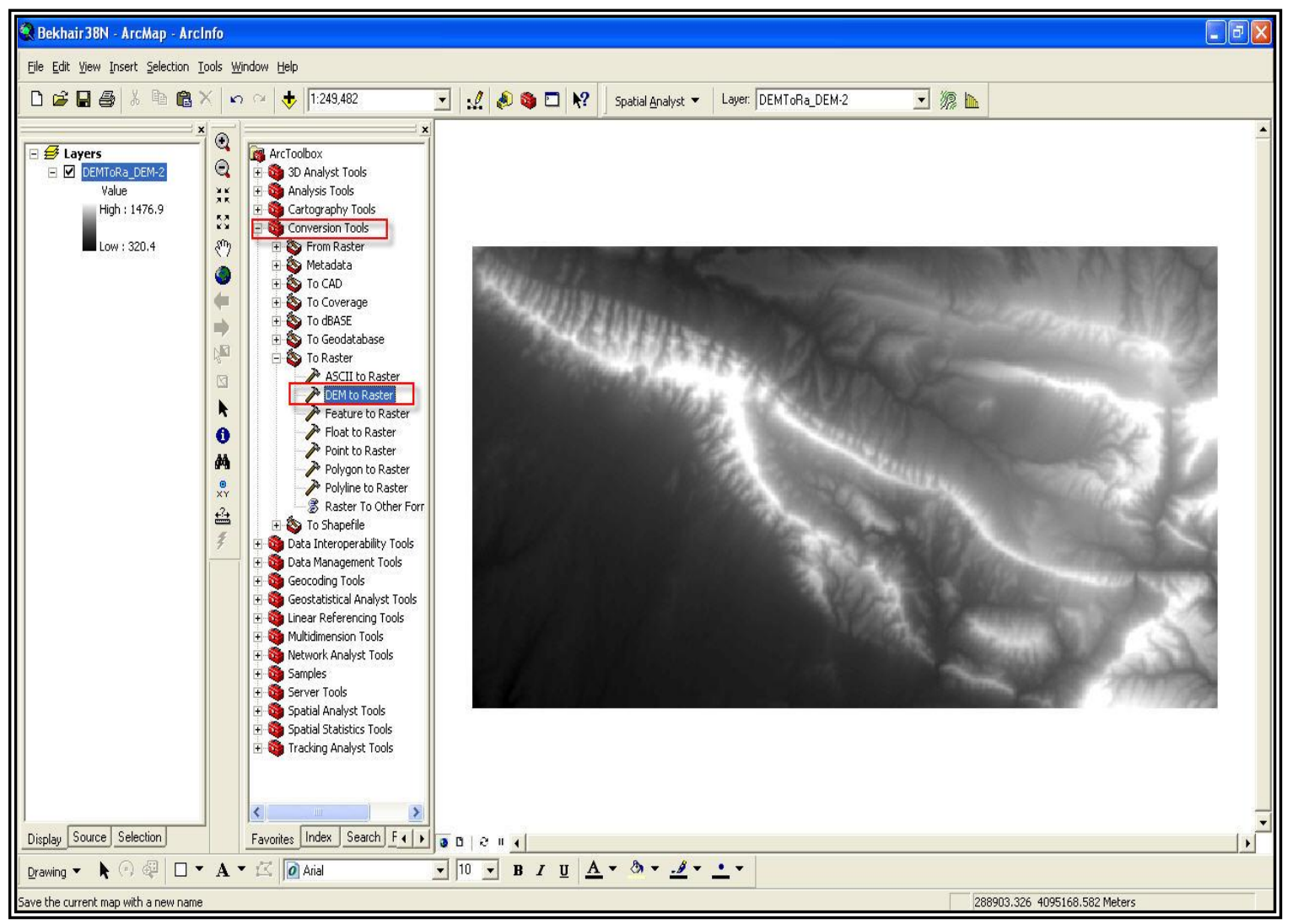

Figure (5): The elevation raster grid of the study area

\section{Results and Discussion:}

Data analysis is the process of interpreting data. This may range from simple exploratory data analysis, which involves simply looking at the data and describing what we see, to complex analysis such as modeling. ArcGIS Spatial Analyst provides a range of spatial modeling and terrain analysis features. This extension allows user to create, query, map, and analyze cell-based raster DEM data and to perform integrated vector-raster analysis. All the required terrain analysis process for study area were completed using ArcGIS9.2 Desktop Package. In this study, the DEM data format have been adopted instead of the triangulated irregular network(TIN) which is depend on the vector data model for the purpose of terrain modeling.

The extracted terrain maps extracted from the figure (5) are: 


\section{1- Contour map:}

The contour map displays an output polyline data set. The value of each line represents all contiguous locations with the same height, magnitude, or concentration of whatever the values on the input data set represent. Based on Jabal Bekhier topographic map which has contour interval $(50 \mathrm{~m})$, the contour map was created contained a classified field for height of contour line, to take the base height in (3D) applications. Figure (6) illustrates the contour map of the study area as display by ArcGIS9.2 Desktop. It is found that the elevation of the area is range from minimum value of $320.4 \mathrm{~m}$ to maximum value of $1476.9 \mathrm{~m}$. This map is an effective way to identify which locations have the same value. It is also useful for surface representation because it allow the analyst to simultaneously visualize flat and steep areas for analyzing the distance between contours.

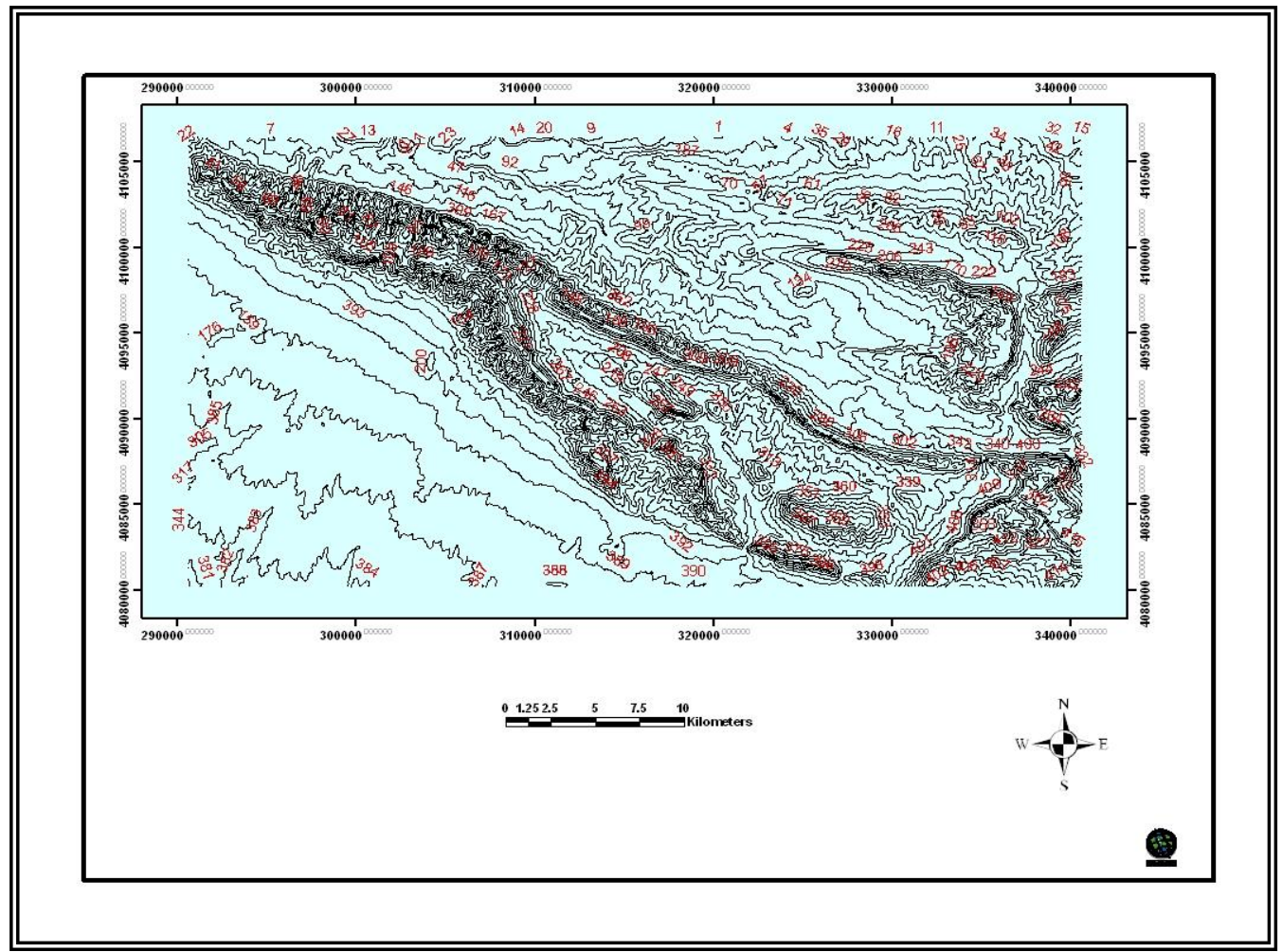

Figure ( 6 ): Contour map of Jabal Bekhier

\section{2- Hill shade map:}

The Hillshade maps are used to determine illumination of a surface for either analysis or graphical display. For analysis, can be used to determine the length of time and intensity of the sun in a given location. For graphical display, Hillshade can greatly used to visually enhance the terrain features. The shaded relief maps of the study area are created from the raster DEM data sets using $45^{\circ}$ (Figure 7) and $75^{\circ}$ (Figure 8) of sun angles and $315^{\circ}$ for sun azimuth. Variations of sun angle and azimuth assist in the Analytical hillshading which is defined as the process of generating realistic highlights and shadows to show the visual relief of 
Spatial Analysis of Jabal Bekhier Elevation by Using GIS and Remote Sensing.

the terrain. These shading patterns help the human eye discern both elevation and form [11]. Also from analytical point of view, it can easy analyze how the landscape is illuminated at various times of the day by lowering and raising of the sun angle. Figures ( 7 and 8) shows that the texture and pattern of certain areas are enhanced.

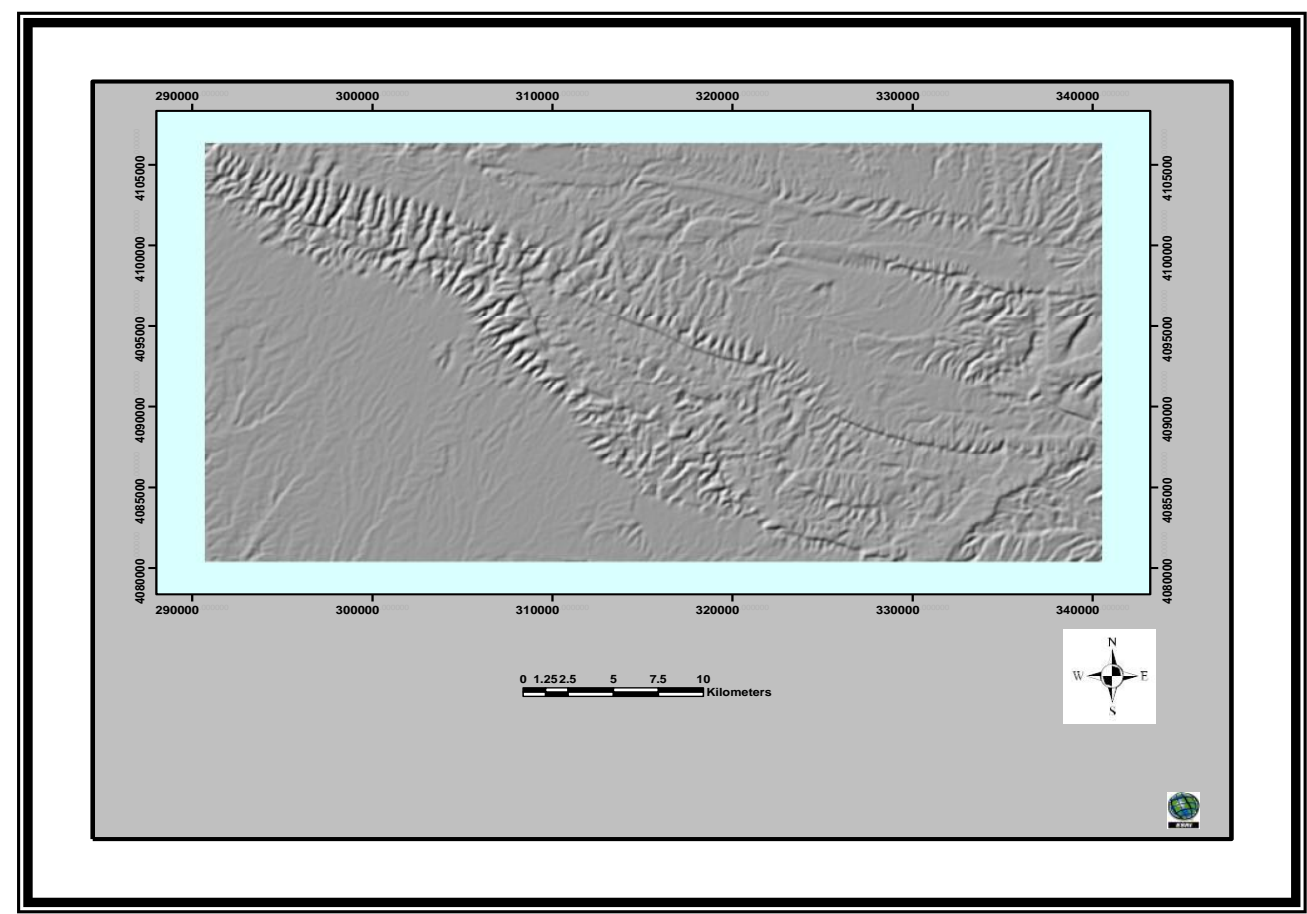

Figure (7): Hillshade map of Jabal Bekhier with sun angle of (45)

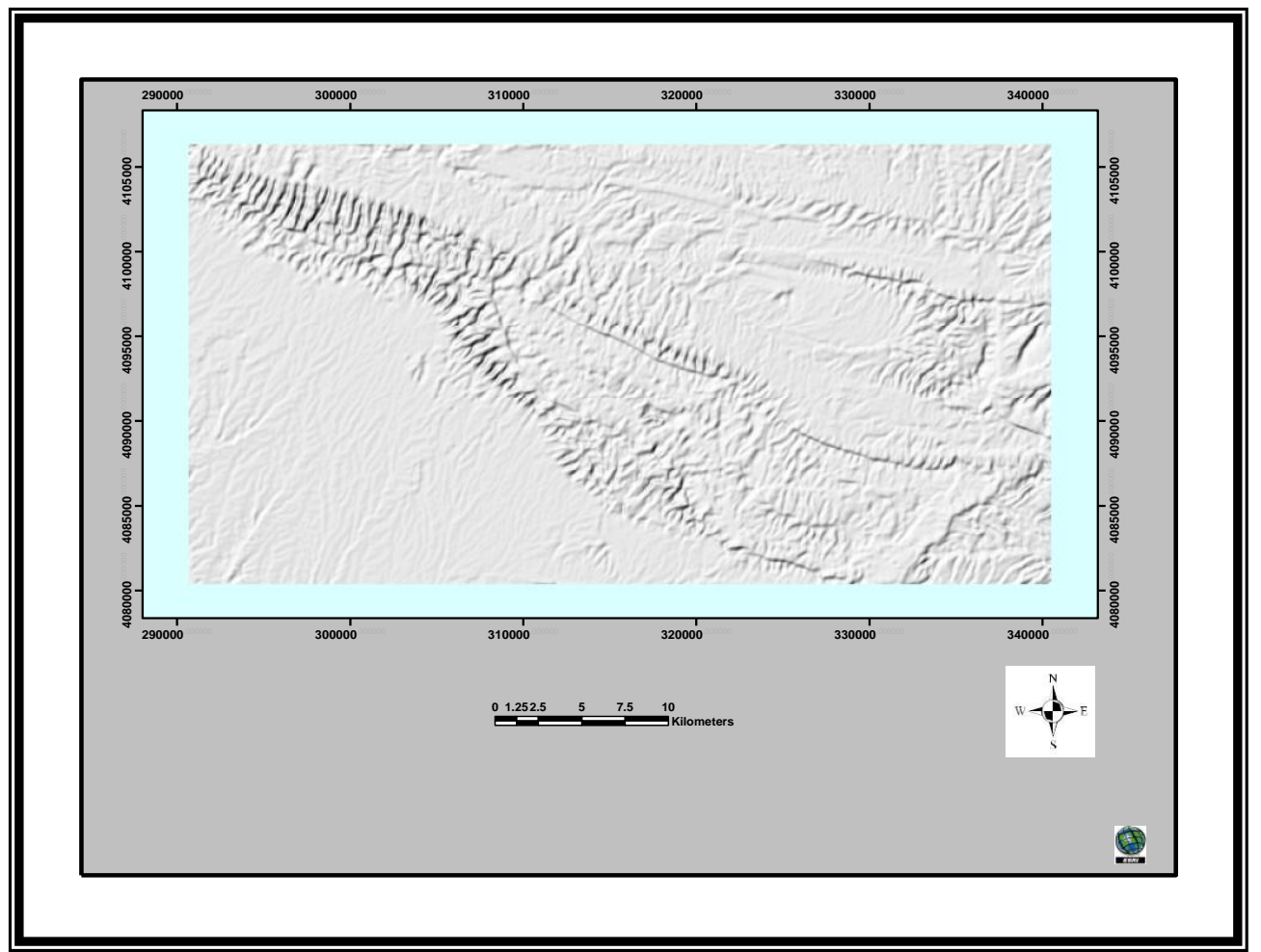

Figure (8): Hillshade map of Jabal Bekhier with sun angle of ( 75) 


\section{3- Slop map:}

The purpose of the slope map is to defined the rate of elevation change from each pixel in the raster DEM its neighbors. The output slop raster data set can be calculated as either a percentage of slop or a degree of slop. In the present study, the percentage of the slope was adopted to defined the angle between the vertical distance change and horizontal distance change. In practice, because DEM image is the discrete grid data, the derivative is computed using finite difference method in each cell's neighborhood. Figure (9) shows the slop feature map of the study area with a default classification of the ArcGIS9.2 Desktop. The maximum slope is $(18.688 \%)$. The map in the figure (9) demonstrates that the steep areas are easy to see, perhaps easier to see than with color and hillshading, and less cluttered than with contours.

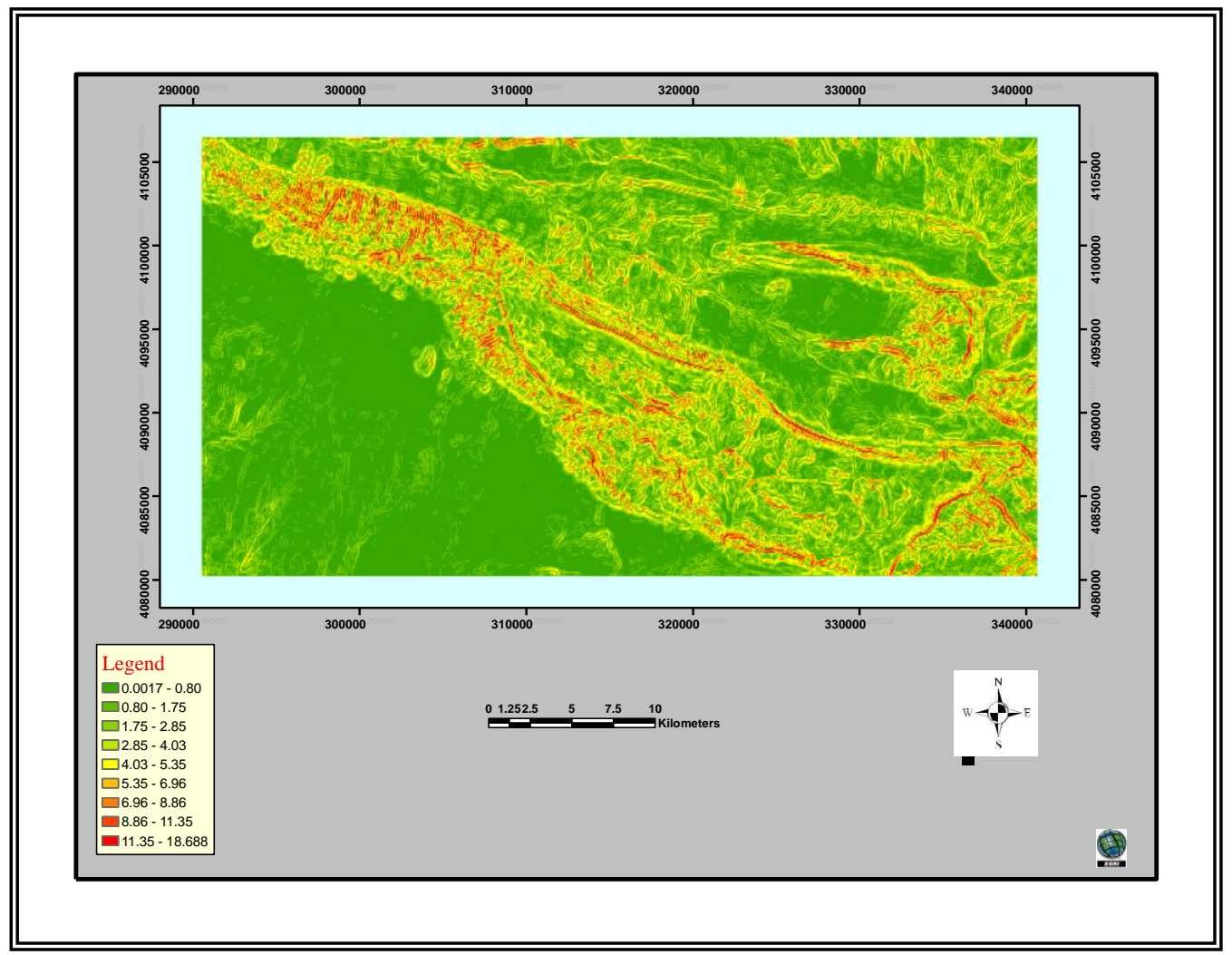

Figure (9): Slop Map of Jabal Bekhier according to ArcGIS9.2 with the default classification

The landscape of the study area was also classified according to table (2) as given by [12] which is give a detail idea about the geomophological units (terrain slop) of the area. According to this approach, the study area can be classified into seven different landscape units 
Spatial Analysis of Jabal Bekhier Elevation by Using GIS and Remote Sensing.

Table (2): The main landscape classification as given by [14]

\begin{tabular}{|c|c|c|}
\hline Relief Unit & Slop Steep (\%) & $\begin{array}{c}\text { Relative Height Different } \\
(\mathrm{m})\end{array}$ \\
\hline Flat & $0-2$ & $2-5$ \\
\hline Undulating / gently & $3-7$ & $5-50$ \\
\hline Undulating / rolling & $8-13$ & $25-75$ \\
\hline Rolling -hilly & $14-20$ & $50-200$ \\
\hline Hilly - steeply & $21-55$ & $200-500$ \\
\hline Steeply & $56-140$ & $500-1000$ \\
\hline Mountain & $>140$ & $>1000$ \\
\hline
\end{tabular}

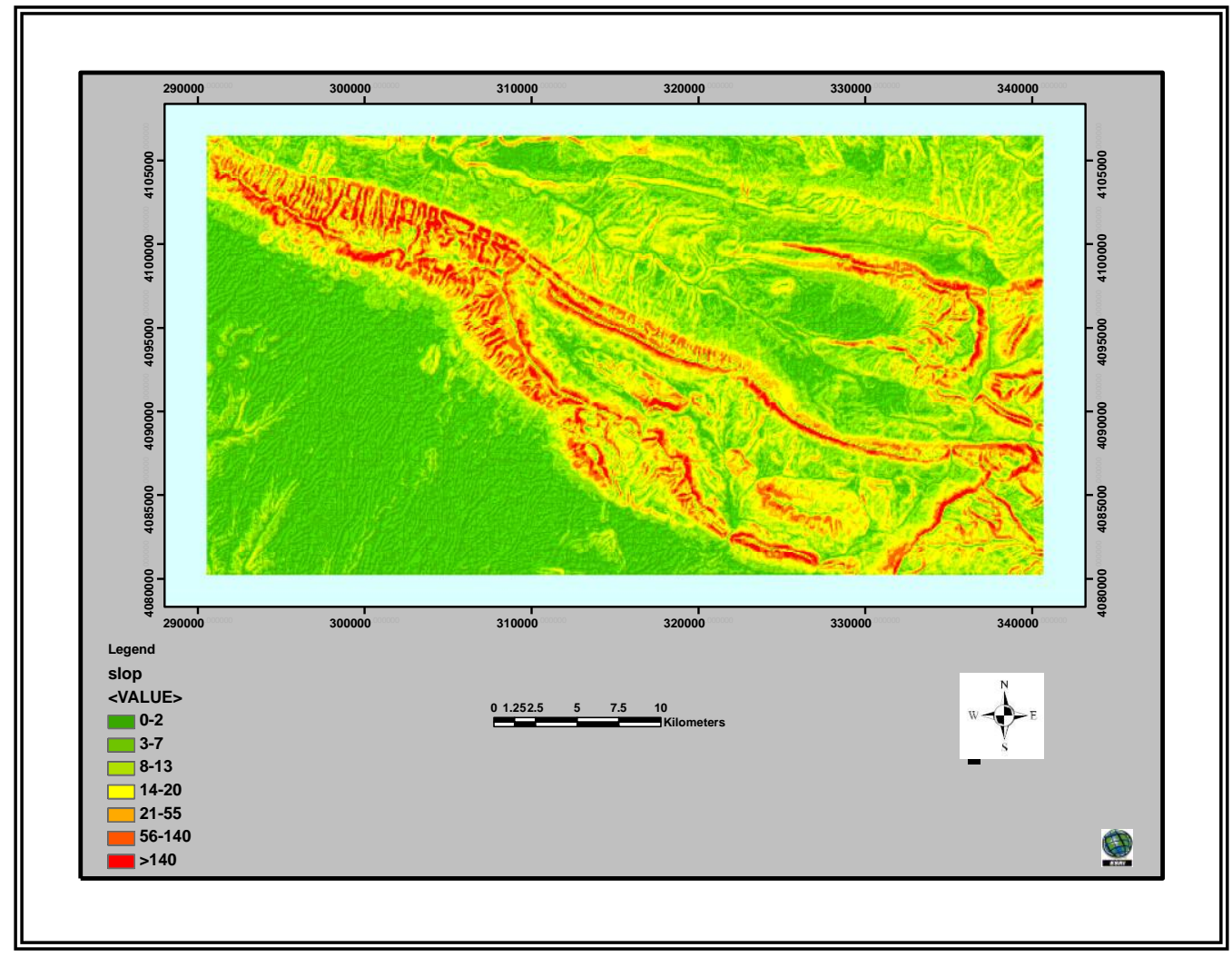

Figure (10): Slop Map of Jabal Bekhier according to table (2)

\section{4- Aspect map:}

Aspect map identifies the steepest down-slope direction from each cell to its neighbors. It could be thought of as the angle between slope direction and the north direction. The angle is expressed in positive degrees from 0 to 360 , measured clockwise starting at 0 from the north [10]. It can be thought of as slope direction or the compass direction of a hill faces. 
Figure (11) shows the color classified Hillshade map of the study area. The Aspect map is a very useful map in the geological analysis, for example in the in forecasting trends in landslides or rocks, which is one of the biggest risks in the countries that fall by the monsoon rains for long periods[13].

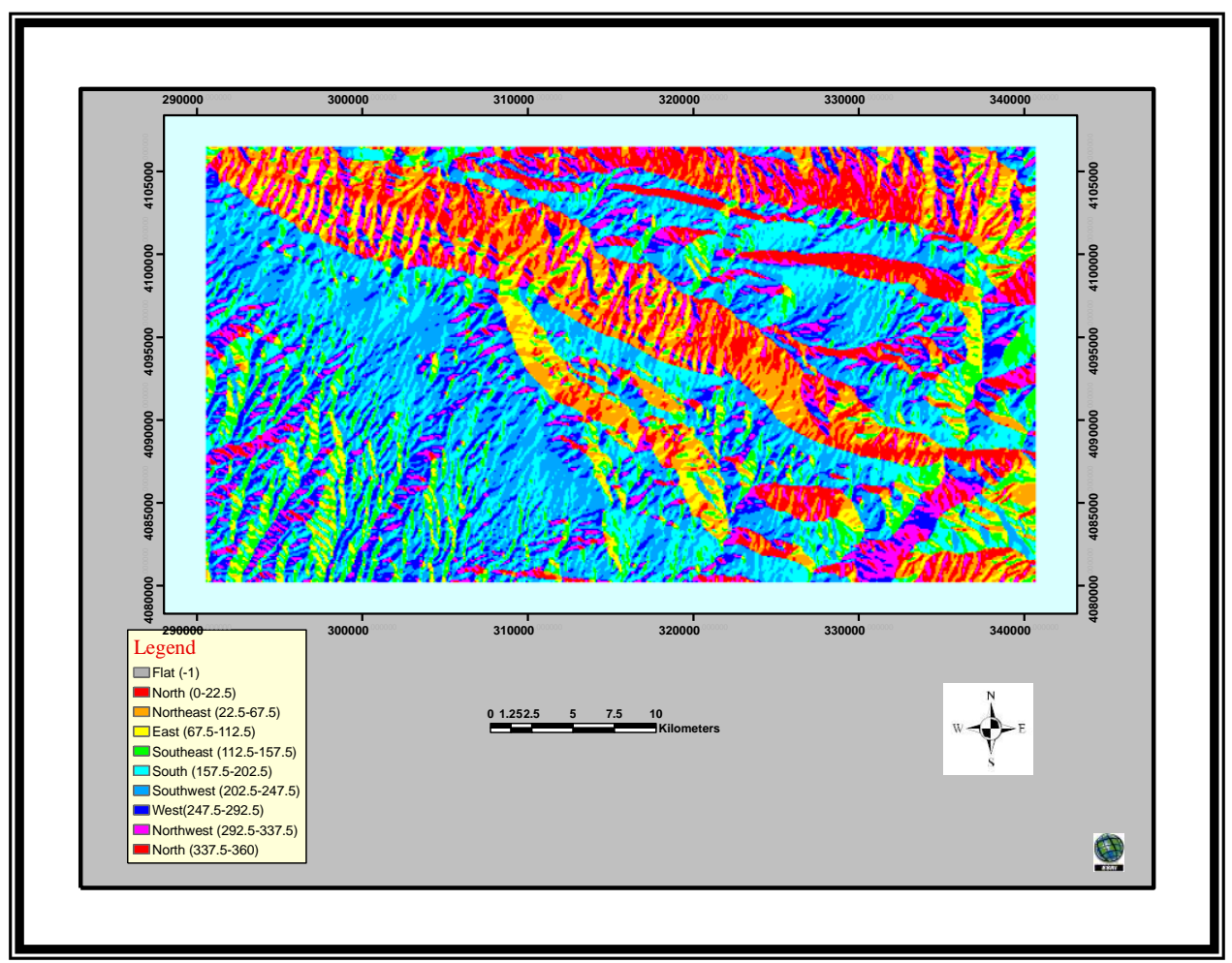

Figure ( 11): Aspect map of Jabal Bekhier

All of the above output maps created from the applying GIS analysis can be gave the decision makers a good idea about the topographic structures of study area, without the GIS, this analysis information would have taken much more time to extract.

\section{7- Conclusions:}

The study of spatial analysis and interpretations of the terrain features in Jabal Bekhier. Successfully demonstrates that the applied GIS methodology is a powerful tool in evaluation and describing the spatial analysis, and mapping of the landscape characteristics (Slop, Aspect, Contour and Hillshade). This is essential to carry out more advanced studies of the complex behavior of geographic process and observed shape, patterns, and morphometric structures of the earth surface. All the resultant digital maps and attributes have been stored as a relational GIS and RS Database System for Jabal Bekhier. The relational GIS and RS Database System for Jabal Bekhier area can be used for retrieval, updating, analyzing and modeling any required map or information. 


\section{References}

1) Thomas, S., Jürgen, B., Andre R., 2006, "Processing of SRTM XSAR Data to correct Interferometric Elevation Model for land surface process applications", Gottinger Geographische Abhandlungen, VOL. 115, pp. 97-128.

2) Sulebak, J. R., 2000, "Applications of Digital Elevation Models", SINTEF Institute of Applied Mathematics, Oslo, pp.1-11.

3) Chrysoulakis, N., Diamandakis, M., Prastacos, P., 2003, "GIS Integration of Aster stereo Imagery for the Support of Watershed Management", 8th International Conference on Environmental Science and Technology, Lemnos island, Greece, pp. 111-118.

4) Al Allawi, M.N.1980., "Structural study of Upper Cretaceous and Tertiary Succession in Jabel bekhair ,Dohuk area, N-Iraq", M.Sc. Thesis, University of Mosul.

5) Lönnqvist, M., Törmä, M., 2006, "Different implications of a spatial boundary /Jebel Bishri between the Desert and the Sown in Syria", Institute for Cultural Research, Department of Archaeology, University of Helsinki, Finland, pp.1-7

6) ArcGIS Desktop, available at: http://www.esri.com/software/arcgis/about/gis_for_me.html, access at: 1-August-2009

7) ArcGIS Spatial Analyst Drive Answers for your Data, available at: http://www.esri.com/software/arcgis/extensions/spatialanalyst/index. html, access at: 5-August-2009

8) Global Mapper Overview, available at: http://www.globalmapper.com/product/overview.htm, access at: 4August-2009.

9) Bresnahan, T. and Dickenson, K., "Surfer 8 Self-Paced Training Guide", Golden Software, Inc., 19P.

10) Tarboton, D. G., "Spatial Field in GIS and Hydrology", Utah University, available at: http://www.engineering.usu.edu/dtarb, accessed at: 28-August-2009.

11) Kennelly, P. J., 2002, "Hillshading with Contours", Journal of Geoscience Education, 50 (4), pp. 428-436.

12) Zuidam, R.A., Zuidam-Cancelado, C., 1979, "Terrain analysis and classification using aerial photographs", ITC textbook of photointerpretation vol. VII-6. ITC, Holland, p.12.

13) Eyad, H. R., Maher, K., Emad, J. A., 2008, "Relational GIS and Remote Sensing Database System for Al-Salt Area, Jordan", American J. of Engineering and Applied Sciences 1 (4), pp.241247. 